\title{
Irrigation patterns in permeable sediments induced by burrow ventilation: a case study of Arenicola marina
}

\author{
Filip J. R. Meysman*, Oleksiy S. Galaktionov, Jack J. Middelburg \\ The Netherlands Institute of Ecology (NIOO-KNAW), Centre for Estuarine and Marine Ecology, Korringaweg 7, \\ 4401 NT Yerseke, The Netherlands
}

\begin{abstract}
In sandy sediments, a strong connection exists between the physics of flow and the ecology of burrow-ventilating macrofauna. We developed a general modelling procedure that quantifies this link involving 3 steps. (1) Burrow-ventilating organisms can be described as mechanical pumps. (2) The pumping of burrow water into blind-ending tubes induces advective flow in the sediment. (3) The resistance to pore water flow is governed by the friction between solid and fluid, i.e. Darcy's law. This analysis allows the determination of the operation point of an 'organism pump' under in situ conditions, and we applied it in a detailed modelling study of the lugworm Arenicola marina. A 3-dimensional finite element model encompasses the lugworm's J-shaped burrow and represents a typical lugworm territory at in situ density. We simulated the associated flow patterns in the sediment and analysed the factors that influence the lugworm's ventilation rate. Since the lugworm's oxygen supply critically depends on the burrow ventilation rate, we advance the following 2 ecological hypotheses: (1) decreasing the permeability of the burrow lining greatly increases the efficiency of oxygen supply, as it prevents the re-entry of anoxic pore water; and (2) the permeability of the bulk sediment constrains the lugworm's habitat. When permeability falls below a critical threshold, the sediment's resistance becomes too high, thus resulting in an insufficient oxygen supply. Overall, we show that permeability exerts an important control on ventilation activity, and hence resource availability, in sandy sediment ecosystems. From an evolutionary point of view, we anticipate biological feedbacks on this physical control - in particular, behavioural adaptations that increase the permeability in the bulk sediment but decrease the permeability near the burrow wall.
\end{abstract}

KEY WORDS: Bio-irrigation • Burrow ventilation • Arenicola marina • Permeable sediments • Modelling

\section{INTRODUCTION}

Benthic ecology is typified by a strong interplay between the 'biology' of the bottom-dwelling organisms and the 'physics' of the sediment environment (Herman et al. 1999, Murray et al. 2002, Reise 2002). It is well recognized that physical parameters, such as grain size, porosity and permeability, strongly constrain the distribution and abundance of benthic macrofauna. However, it is also understood that this physical control is not exclusive and unidirectional.
Benthic organisms can actively alter the physical state of the sediment environment to enhance their own living conditions and influence those of other organisms (Levinton 1995, Reise 2002), a concept more generally known as 'ecosystem engineering' (Jones et al. 1994).

An important example of ecosystem engineering in the benthic environment is the process of burrow ventilation (Aller 1980, 2001, Herman et al. 1999, Meile \& Van Cappellen 2003). Infaunal polychaetes, crustaceans and bivalves create burrows that deeply penetrate into the anoxic zone of the sediment (e.g. Gust \& 
Harisson 1981, Ziebis et al. 1996, Koretsky et al. 2002). The metabolic need for oxygen is satisfied by ventilation of these burrows with oxygen-rich water from the overlying water column. Due to this 'active' burrow ventilation, the organisms are no longer restricted to the narrow zone near the sediment surface where oxygen penetrates via 'passive' diffusion.

One important issue, which has not received much attention in past studies, is that the mechanism of burrow ventilation crucially depends on the permeability of the sediment. One can consider 2 end-member situations (Fig. 1). In muddy environments, the pressures required to force a flow of pore water through the sediment are typically beyond the physiological capabilities of benthic fauna. To enable burrow ventilation, burrows must have at least 2 connected openings to the sediment surface, to ensure a free conduit for the ventilated burrow water (Fig. 1a). So, in muddy sediments, advective flows are generated within the burrow, but these flows do not penetrate the surrounding sediment. Therefore, the bio-irrigational exchange of solutes between burrow water and pore water principally occurs by diffusion across the burrow walls. This diffusive mechanism creates distinct geochemical gradients around the burrow structures (Aller 1980). In sandy environments, the effect of burrow ventilation can be equally pronounced, though the connection between ventilation and bio-irrigation is different. Due to the higher permeability, organisms can actively pump water across blind ends of burrows into the surrounding sediment (Fig. 1b), and, as a result, burrows no longer need a 2-way connection to the surface (Foster-Smith 1978). So, in sandy sediments, the flows that are generated within the burrow can penetrate the surrounding sediment, and solute transfer between burrow water and the pore water is due to an advective mechanism. The advective flows that are generated in the pore water can have an important influence on the overall biogeochemistry and microbial ecology of the sediment (e.g. Huettel 1990, Banta et al. 1999).

Here, we propose a modelling procedure to quantitatively expose the pore water flow patterns generated by burrow ventilation in permeable sediments. The aim is to investigate the ecological implications of this advective irrigation, especially the consequences for burrow construction and habitat selection. Our approach focuses on the lugworm Arenicola marina as a representative example of a burrow-ventilating organism and derives flow patterns from a comprehensive 3D model of the organism's burrow and the surrounding sediment.

We selected Arenicola marina as our study species for 2 specific reasons. Firstly, arenicolid polychaetes constitute a dominant type of bio-irrigators in temperate, near-shore, sandy environments (Reise 1985). Secondly, being a well-studied benthic organism, a substantial amount of background information on the ecology and ventilation of Arenicola has been gathered (see review by Riisgård \& Banta 1998). Likewise, the reason for our exclusively modelling-based approach is principally the lack of appropriate experimental techniques. With present-day technology, it is (a) Muddy sediments

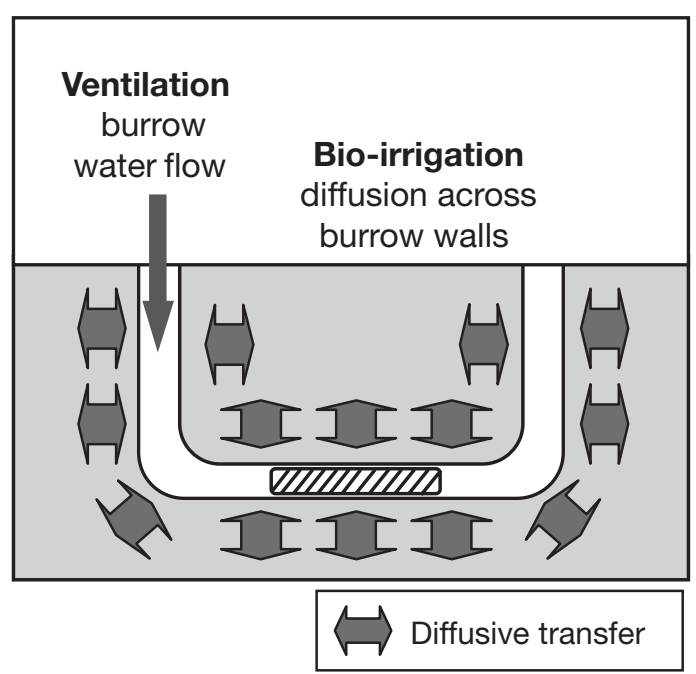

(b) Sandy sediments

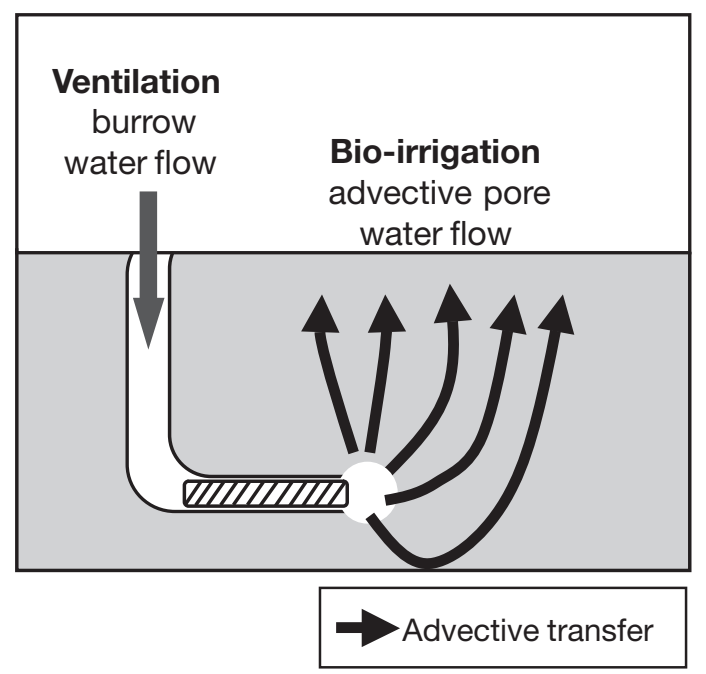

Fig. 1. The link between burrow ventilation (the bulk flow of burrow water) and bio-irrigation (the transport of solutes in the pore water) depends on the permeability of the sediment. (a) Muddy sediments: burrows have 2 or more connections to the surface; bio-irrigational transport is driven by diffusion across the burrow walls. (b) Sandy sediments: burrows may end blindly within the sediment; bio-irrigational transport is driven by advective flows of pore water 
not yet possible to quantify the pressure and velocity field with a satisfactory resolution on the scale of the lugworm. Even if sufficiently small pressure transducers and flow probes were available, they would only provide point measurements, which would reveal little information on the complex 3D pressure or flow field. Faced with this lack of experimental capabilities, numerical modelling offers an opportunity to investigate sediment irrigation at high resolutions.

\section{VENTILATION ACTIVITY}

\section{Ecology}

The polychaete taxon Arenicolidae, commonly known as lugworms, comprises a group of depositfeeding polychaetes with a worldwide occurrence (Rouse \& Pleijel 2001). One member, Arenicola marina, is a large head-down deposit feeder (12 to $24 \mathrm{~cm}$ long) inhabiting the intertidal sand flats of western Europe. This polychaete can be found in considerable densities (up to 50 ind. $\mathrm{m}^{-2}$ ) in clean to muddy sand throughout most of its geographical range from the Arctic to the Mediterranean (Riisgård \& Banta 1998). Sometimes, it represents half of the total macrofaunal biomass on the lower shore (Cadee 1976, Beukema \& De Vlas 1979).

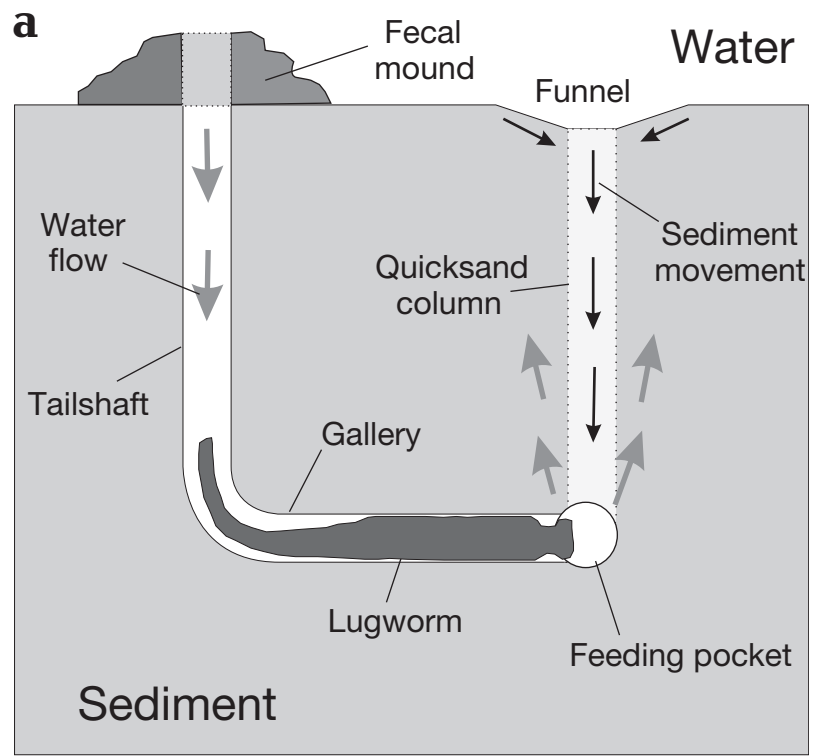

Lugworms dwell in J-shaped burrows (Fig. 2a) that may reach depths of up to $20-40 \mathrm{~cm}$, depending on age and size-class (Wells 1945, Kruger 1959). When feeding, the worm resides in the lower part of the burrow called the 'gallery'. Positioned head down, Arenicola marina ingests sediment from a feeding pocket at the closed end of the gallery, which is enveloped by coarse-grained sediment particles. This feeding mode causes a downward transport of sediment above the feeding pocket, and leads to the formation of a socalled 'quicksand column', a cylinder of loosened sediment that is sometimes visible on the sediment surface as a funnel (Jakobsen 1967, Rijken 1979, Retraubun et al. 1996). When defecating, the worm moves backwards along the burrow until its tail reaches the surface. At the open end of the burrow, the residual sediment is ejected, which produces the characteristic faecal mounds.

The direction of the water flow generated by Arenicola marina is opposite to the sediment transport by ingestion-egestion. Residing in the gallery, the lugworm pumps water by means of piston-like waves that run along its dorsal surface (Kruger 1971). The suction created by these peristaltic motions takes in oxygenated water from the overlying water column. Passing through the burrow and over the lugworm's gills, this water is subsequently pumped through the porous walls of the feeding pocket into the surrounding sedi-

b

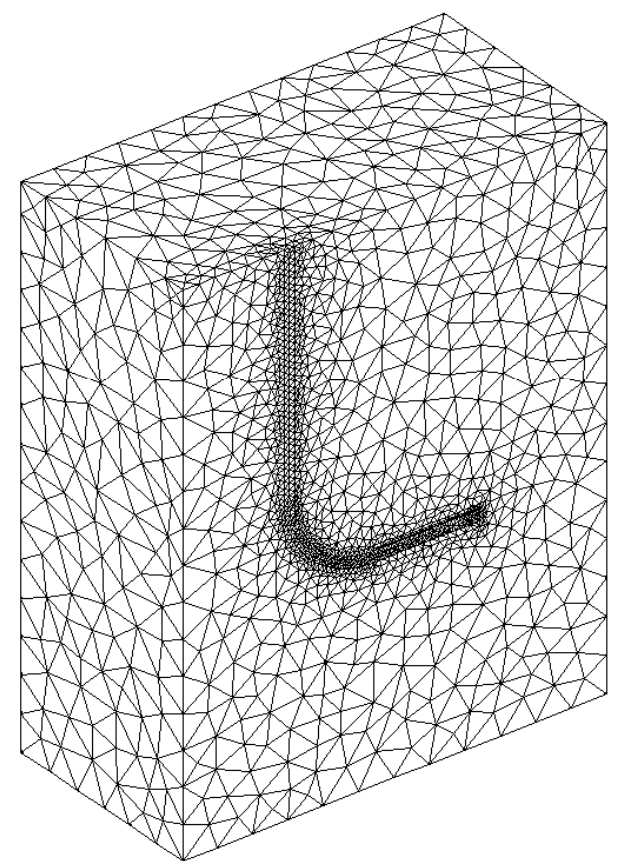

Fig. 2. (a) Schematic representation of the counter current flows of water and sediment induced by Arenicola marina. The link between burrow ventilation and bio-irrigation is the advective mechanism depicted in Fig 1b. (b) Finite element mesh around the lugworm burrow used in the simulations. Due to symmetry only half of the domain needs to be meshed. A finer mesh resolution is adopted near the burrow wall 
ment. The latter then results in an upward, advective transport of pore water through the sediment to the sediment surface. Our aim is to quantify this irrigation pattern using a 3D flow model.

\section{Modelling approach}

Past studies of lugworm ventilation have primarily focused on the organism itself, while devoting far less attention to its environment. Particularly, the pumping activity of Arenicola marina has been characterised in great detail in glass tubes under laboratory conditions (Foster-Smith 1978, Baumfalk 1979, Riisgård et al. 1996). Yet, to transpose these results to the field situation, highly simplified models of the sediment environment were used. In these models, the flow pattern caused by A. marina is a priori assumed to be $1 \mathrm{D}$, i.e. pore water moves uniformly upwards through a core of constant radius (Riisgård et al. 1996, Timmermann et al. 2002, 2003).

Here, our ambition is to implement the available information on Arenicola pumping in a more sophisticated model of the lugworm's sediment habitat. Rather than imposing a preconceived flow pattern, the idea is to obtain this pattern as the output of the model. For this purpose, we propose a detailed 3D finite element model (FEM) of the lugworm burrow and the surrounding sediment. The driving force that generates flow in porous media is not the fluid pressure $p$, but the pressure in excess over the hydrostatic pressure, which is typically expressed as the hydraulic head $H$ (Bear 1972, Freeze \& Cherry 1979). The precise relation between $H, p$ and the pore water velocity vector $\mathbf{v}$ is detailed below. Accordingly, we will develop a model that describes the spatial variation of $H$ and $\mathbf{v}$ within a specific 3D lugworm territory. In this model description, we implement the following idealisations: (1) the lugworm's ventilation rate is constant over time; and (2) the sediment surrounding the burrow has homogeneous properties. These assumptions will be discussed in detail below.

\section{THE ARENICOLA PUMP}

To investigate the pumping activity of benthic organisms, one can apply the same engineering principles as in the analysis of (abiotic) mechanical pumps (Foster-Smith 1979). To this end, one needs to idealize the lugworm's ventilation activity with an appropriate pumping mechanism, and, subsequently, translate the technical concepts 'pump characteristic' and 'system characteristic' in terms of the lugworm's situation.

\section{Pumping mechanism}

Riisgård et al. (1996) made a detailed analysis of what is referred to as the 'Arenicola pump' in order to assess the energetic costs of pumping. Basically, the Arenicola pump was found to approximate an ideal, closed, positive-displacement pump. In general, a pump is termed ideal when it possesses perfect piston seals and shows no leakage to the suction section (i.e. no slippage). This implies that a constant displacement volume $V_{\mathrm{d}}$ is maintained irrespective of the flow resistance in the system in which the pump is operating. Accordingly, the frequency $f$ at which an ideal pump operates is the only factor that affects the flow rate $Q$, i.e. $Q=f V_{\mathrm{d}}$. In the case of Arenicola, the term $f$ denotes the stroke frequency of the peristaltic tail-to-head undulations.

As noted above, we assume that the lugworm continuously pumps with a steady pumping rate. However, in reality, the lugworm's ventilation activity shows 2 characteristic scales of temporal variability. Firstly, on a short time-scale, the peristaltic undulations generate a pulsed flow with a typical stroke frequency of $f=$ $7 \min ^{-1}$ (Riisgård et al. 1996). Piston pumps pulsate by nature, and, in this regard, the Arenicola pump does not differ from its mechanical counterparts. However, in technical calculations, this high-frequency pulsating flow is generally replaced by its time-averaged value. The latter approach is equally justifiable for the Arenicola pump. Due to the linearity of Darcy's law (see section 'System characteristic'), the time-average of the sediment pressure loss will scale with the time-average of the pulsating flow. Accordingly, no major (nonlinear) deviations in the flow pattern are expected due to the pulsations. Secondly, the pumping rate also varies on a longer time-scale, as the lugworm's ventilation activity proceeds in regular cycles of 40 to $60 \mathrm{~min}$ that are probably under the control of a pacemaker in the nervous system (Wells 1949, Kruger 1971). This ventilation pattern differs in 2 ways from that of other burrow ventilators. Firstly, Arenicola shows long periods of continuous pumping, only interrupted by short periods of inactivity related to defecation at the surface (Baumfalk 1979). This contrasts markedly to other tube-dwelling organisms, such as thalassinidean shrimp (Forster \& Graf 1995) and nereid polychaetes (Kristensen 2001), which show intermittent ventilation, i.e. far longer periods of rests interspersed by short bursts of ventilation activity. Secondly, during ventilation, the pumping rate is almost steady, which contrasts strongly with the irregular ventilation pattern of nereid polychaetes (Kristensen 2001). Together, these arguments indicate that the lugworm's ventilation activity can be acceptably characterised in terms of a mechanical piston pump that operates in a steady and continuous fashion. 


\section{Pump characteristic}

A pump's performance is typically summarised in a pump characteristic, a curve that plots the flow rate $Q$, which a given pump can develop against a certain pressure difference across the pump. This pressure difference across the pump is expressed as a difference in $H$, i.e. the pump head $\Delta H_{\mathrm{p}}\left(\mathrm{cm} \mathrm{H} \mathrm{H}_{2} \mathrm{O}\right)$. For most pumps - whether mechanical or biological - there is a marked trade-off between the variables in the pump characteristic. Higher flow rates can only be pumped over smaller pressure differences, i.e. $\Delta H_{\mathrm{p}}$ decreases when $Q$ increases.

Employing an inventive experimental set-up, Riisgård et al. (1996) monitored the stroke frequency and the pumping rate of individual Arenicola marina. For this purpose, the organisms were enclosed in a horizontally placed Plexiglas tube. For a given pressure difference $\Delta H_{\mathrm{p}}$ imposed between the inlet and outlet of the glass tube, $Q$ was measured. Based on measurements for 3 separate worms, the following relation was obtained as the Arenicola pump characteristic:

$$
\Delta H_{\mathrm{p}}(Q)=\Delta H_{\mathrm{p}}^{\max }\left[1-\left(\frac{Q}{Q^{\max }}\right)^{2}\right]
$$

where $\Delta H_{\mathrm{p}}^{\max }$ is the pump's maximal reachable pump head (i.e. when the flow rate vanishes) and $Q^{\max }$ refers to the maximal obtainable flow rate (i.e. when the pressure difference that needs to be overcome approaches zero). In fact, many benthic bio-irrigating organisms show a similar quadratic pump characteristic with the species-specific parameters $\Delta H_{\mathrm{p}}^{\max }$ and $Q^{\max }$ (Foster-Smith 1979). Riisgård et al. (1996) found that both parameters had remarkably similar values for different Arenicola individuals. This led these authors to introduce the concept of a 'standard Arenicola worm', characterised by $\Delta H_{\mathrm{p}}^{\max }=20 \mathrm{~cm} \mathrm{H}_{2} \mathrm{O}$ and $Q^{\max }=1.5 \mathrm{ml}$ min $^{-1}$ (see Riisgård et al. 1996 for the experimental data upon which these values are based). This 'standard pump characteristic' is used in all simulations below (Table 1).

\section{System characteristic}

Technically, a pump can operate in distinct environments, each characterised by a different resistance to flow. This dependence is captured by a second curve, termed the system characteristic, which depicts the system's pressure loss as a function of $Q$. The system's pressure loss is expressed by system head $\Delta H_{\mathrm{s}}$, which typically will increase with the flow. In the case of the Arenicola pump, $\Delta H_{\mathrm{s}}$ originates from a number of factors: (1) the resistance to water flow in the tail shaft tube; (2) the frictional loss when the water passes between the worm's body and the gallery wall; and (3) the pressure drop in the sediment between the feeding pocket and the sediment surface. Riisgård et al. (1996) estimated that the total pressure drop due to the first 2 factors only amounts to about $0.01 \mathrm{~cm} \mathrm{H}_{2} \mathrm{O}$, which can be neglected as compared to the flow resistance in the sediment. Hence, we equate the system's pressure loss solely to the frictional resistance to pore water flow in the sediment surrounding the Arenicola burrow.

The frictional resistance to pore water flow in sediments is generally modelled by Darcy's law. When applying Darcy's law to a particular sediment domain, one always obtains a linear relation between the system's pressure loss and the flow rate, referred to as the system characteristic:

$$
\Delta H_{\mathrm{s}}(Q)=C_{f} Q
$$

where $C_{f}$ is termed the resistance coefficient. The actual proof that Darcy's law always yields a linear system characteristic (Eq. 2) is discussed in detail below. Note that the system characteristic (Eq. 2) applies to a specific sediment domain. In other words, to establish the system characteristic for the Arenicola pump under natural conditions, we need to delineate a suitable 'Arenicola territory', i.e. a representative sediment domain that sufficiently encompasses the pore water flow pattern near the burrow of an individual lugworm. In contrast to the pump characteristic (Eq. 1), which incorporates 2 parameters, the system characteristic (Eq. 2) only features 1 parameter, $C_{f}$. Remark-
Table 1. The default parameter set employed in the simulations. The parameter values represent an average lugworm (a 'standard Arenicola worm') with a typical burrow structure (a 'standard Arenicola burrow') in a typical sediment territory (a 'standard Arenicola domain')

\begin{tabular}{|llcc|}
\hline Parameter & Description & Value & Unit \\
\hline Pump characteristic & & & \\
$Q^{\max }$ & Maximal obtainable flow rate & 90 & $\mathrm{~cm}^{3} \mathrm{~h}^{-1}$ \\
$\Delta H_{\mathrm{p}}^{\max }$ & Maximal reachable pump head & 20 & $\mathrm{~cm} \mathrm{H}_{2} \mathrm{O}$ \\
Territory & & & \\
$L_{\mathrm{L}}$ & Length lugworm territory & 20 & $\mathrm{~cm}$ \\
$L_{\mathrm{W}}$ & Width lugworm territory & 20 & $\mathrm{Cm}$ \\
$L_{\mathrm{D}}$ & Depth model domain & 25 & $\mathrm{Cm}$ \\
$\phi$ & Porosity & 0.5 & - \\
$k$ & Permeability & $2.5 \times 10^{-11}$ & $\mathrm{~m}^{2}$ \\
Burrow & & & \\
$L_{\mathrm{shaft}}$ & Length tail shaft & 15 & $\mathrm{~cm}$ \\
$L_{\mathrm{gal}}$ & Length gallery & 9 & $\mathrm{~cm}$ \\
$R_{\mathrm{b}}$ & Radius burrow & 0.25 & $\mathrm{~cm}$ \\
$R_{\mathrm{fp}}$ & Radius feeding pocket & 0.25 & $\mathrm{~cm}$ \\
\hline
\end{tabular}


ably, this implies that all the factors that influence the resistance to flow in a particular Arenicola territory are condensed into a single proportionality constant. As shown below, the resistance coefficient $C_{f}$ is dependent on the territory's geometry (determined by 'biological' parameters such as organism density and burrow shape), as well as on intrinsic resistance to flow in the sediment (determined by 'physical' parameters such as sediment permeability and pore water viscosity).

\section{Operating point}

The pump's actual operating point is where the pressure difference generated by the pump matches the pressure difference due to frictional loss in the pump's environment. Graphically (Fig. 3), this operating point can be determined as the intersection of the quadratic pump characteristic (Eq. 1) and the linear system characteristic (Eq. 2). Analytically, the pumping rate at the operating point (denoted $Q^{\text {op }}$ ) can be derived by equating the pump characteristic (Eq. 1) and the system characteristic (Eq. 2), yielding the quadratic equation:

$$
\left(\frac{Q^{\mathrm{op}}}{Q^{\max }}\right)^{2}+\frac{C_{f}}{\Delta H_{\mathrm{p}}^{\max }} Q^{\mathrm{op}}-1=0
$$

As noted above, Riisgård et al. (1996) determined the parameters $\Delta H_{\mathrm{p}}^{\max }$ and $\mathrm{Q}^{\max }$ for a representative lugworm individual, a so-called 'standard Arenicola worm' (Table 1). Accordingly, the only unknown para-

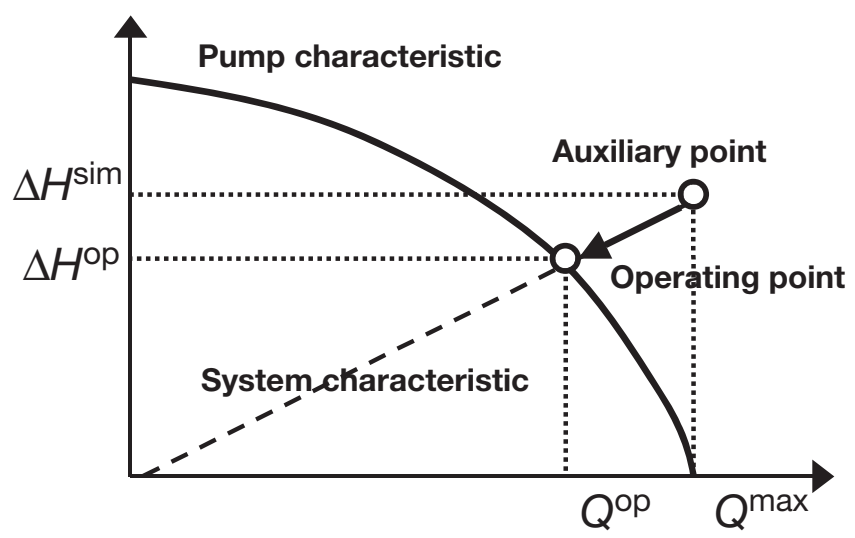

Fig. 3. Procedure to arrive at the operating point of the lugworm pump. In a first step, the pressure head $\Delta H^{\text {sim }}$ that corresponds to the maximal pumping rate $Q^{\max }$ is obtained from the simulation output. Subsequently, the system characteristic is drawn as the line through the origin and the auxiliary point $\left(Q^{\max }, \Delta H^{\mathrm{sim}}\right)$. Finally, the operation point of the lugworm pump is determined as the intersection between system characteristic and pump characteristic meter in Eq. (3) is the resistance coefficient $C_{f}$. In other words, the problem of finding the operation point of the Arenicola pump in the sediment comes down to the determination of $C_{f}$ for a suitable Arenicola territory. This calculation procedure is detailed in the following sections. To simplify terminology, we will from now on refer to $C_{f}$ as the 'resistance coefficient', while actually meaning 'the frictional resistance coefficient in the system characteristic for a representative Arenicola territory'.

\section{D MODEL APPROACH}

To date, only crude approximations have been presented to obtain specific $C_{f}$ values. Typically, one defines a so-called 'representative percolation volume' (RPV) above the feeding pocket through which the burrow water flows back to the sediment surface (e.g. Riisgård et al. 1996, Timmermann et al. 2002). Assuming a laterally uniform flow field in this column, one applies the 1D version of Darcy's law (Bear 1972, Freeze \& Cherry 1979):

$$
Q=\frac{A^{\mathrm{RPV}}}{L^{\mathrm{RPV}}} K \Delta H_{\mathrm{s}}
$$

where $K$ denotes the hydraulic conductivity, while $L^{\mathrm{RPV}}$ and $A^{\mathrm{RPV}}$, respectively, denote the depth and crosssectional area of the RPV. Comparing Eqs. (2) \& (4) yields:

$$
C_{f}=K^{-1} \frac{L^{\mathrm{RPV}}}{A^{\mathrm{RPV}}}=\alpha_{1 \mathrm{D}} K^{-1}
$$

where we have introduced the proportionality constant $\alpha_{1 \mathrm{D}}=L^{\mathrm{RPV}} / A^{\mathrm{RPV}}$, which characterises the geometry of the RPV. Eq. (5) shows that sediment resistance is dependent on the geometrical factor $\alpha_{1 \mathrm{D}}$ and on $K$. Consequently, one can explicitly calculate $C_{f}$ provided that accurate values can be determined for each of the parameters in Eq. (5). $K$ is a physical parameter that is readily amenable to experimental evaluation. For example, Riisgård et al. (1996) determined a $K$-value of $5 \times 10^{-4} \mathrm{~m} \mathrm{~s}^{-1}$ for the sediment from which Arenicola specimens were collected. Furthermore, $L^{\mathrm{RPV}}$ is typically taken to be equal to the depth of the gallery in the Arenicola burrow (Riisgård et al. 1996, Timmermann et al. 2002). Nevertheless, the specification of an appropriate value for the 'representative area' $A^{\mathrm{RPV}}$ is problematic. The principal difficulty is the inherent subjectivity associated with the selection of the RPV above the feeding pocket. In reality, the feeding pocket is a 3D object, and, hence, the velocity field near the feeding pocket is likely to be 3D in nature. The RPV concept greatly simplifies this complex flow pattern by mapping it into an averaged $1 \mathrm{D}$ representa- 
tion with unidirectional flow. Consequently, the extent of $A^{\mathrm{RPV}}$ cannot be assessed experimentally, as it has only a conceptual meaning. Therefore, any $C_{f}$ values calculated from Eq. (5) must be regarded as approximate and qualitative, as they are based on an 'intelligent guess' for $A^{\mathrm{RPV}}$. For example, Riisgård et al. (1996) postulated a value of $5.5 \mathrm{~cm}^{2}$ for $A^{\mathrm{RPV}}$ in order to arrive at resistance coefficients, while Timmermann et al. (2002) estimated $A^{\mathrm{RPV}}$ values (5.5 to $29 \mathrm{~cm}^{2}$ ) by fitting a $1 \mathrm{D}$ reactive transport model to experimental tracer profiles.

\section{D MODEL APPROACH}

The 1D application of Darcy's law (Eq. 4) proves unsatisfactory, as it specifies the flow pattern a priori and employs a subjective delineation of the percolation volume. In reality, the flow pattern induced by Arenicola ventilation is $3 \mathrm{D}$ in nature, and therefore we now approach the problem of determining $C_{f}$ in a full 3D fashion. To this end, we will (1) demarcate a suitable 3D sediment domain enclosing the Arenicola burrow, (2) apply Darcy's law to this 3D setting, (3) specify appropriate boundary conditions and (4) solve the corresponding equation set. In this way, the flow pattern-or equally the 'percolation volume'-is no longer imposed a priori, but is obtained a posteriori as the output of the model.

\section{D model domain}

Assuming non-overlapping territories of equal size, a rectangular sediment block surrounding the J-shaped Arenicola burrow was selected as the 3D model sediment domain (Fig. 2). On top, the model domain is delineated by the sediment-water interface (SWI). We neglect the depression of the feeding pit and the protrusion of the defecation mound, so the SWI is modelled as a flat surface. The size of this 'Arenicola domain' should correspond to representative lugworm densities on intertidal flats. Adopting an average worm density of 25 animals $\mathrm{m}^{-2}$ (Beukema \& De Vlas 1979), we arrive at a horizontal square cross-section of length $L_{\mathrm{L}}=20 \mathrm{~cm}$ and width $L_{\mathrm{W}}=20 \mathrm{~cm}$ (Fig. 2).

The worm burrow is placed in the middle plane of the sediment block, and its dimensions are chosen to represent a 'standard Arenicola burrow'. Note that by placing the burrow in the middle plane, the Arenicola domain becomes symmetrical, and hence only half of the sediment block has to be effectively modelled. The J-shaped burrow has a curved cylindrical form of constant radius $R_{\mathrm{b}}=2.5 \mathrm{~mm}$. The horizontal gallery has a length $L_{\text {gal }}=9 \mathrm{~cm}$ and is located at a depth of $L_{\text {shaft }}=$
$15 \mathrm{~cm}$ (Fig. 2). The feeding pocket is a sphere of radius $R_{\mathrm{fp}}$ at the end of the gallery. In the absence of geometrical data on the feeding pocket, we assume that it has the same radius as the burrow, i.e. $R_{\mathrm{fp}}=R_{\mathrm{b}}$. The burrow's shape was described analytically using the standard geometrical shape functions available in FEMLAB (www.comsol.com). Note that the burrow itself consists of water, and hence does not belong to the modelled sediment domain. The positioning of the burrow within the middle plane is to some extent arbitrary. We opted for the most central position, placing the gallery symmetrically around the central vertical axis. In this arrangement, the tail shaft and feeding pocket are at equal distance from this central axis. The sensitivity of the model results to this particular burrow arrangement was checked a posteriori. Small horizontal translations $(<3 \mathrm{~cm})$ of the burrow to either side of the central axis did not influence the results significantly. Larger translations did have an effect, causing boundary effects when either the feeding pocket or the tail shaft were too near to the lateral side of the domain. However, since the lugworm is a territorial organism, we consider such arrangements not representative for actual conditions in the field. The lower boundary of the model domain was chosen to be $L_{\mathrm{D}}=$ $25 \mathrm{~cm}$. By setting this lower boundary sufficiently deep (i.e. $10 \mathrm{~cm}$ below the gallery depth), we found that the simulation results are virtually the same for a semiinfinite domain, and thus boundary effects were avoided.

As a simplifying idealisation, we assume that the sediment has uniform properties (porosity, permeability) within the Arenicola domain. However, under natural conditions, it has been observed that sediment reworking by benthic organisms has an influence on sediment properties (Meadows \& Tait 1989). For the specific case of $A$. marina, 2 types of spatial heterogeneity are generally put forward. Horizontally, a coarse sediment layer is often observed at the level of the gallery and the feeding pocket, attributed to selective particle ingestion (Reise 2002). Because the lugworm selectively ingests the smaller particles, the coarser ones (e.g. shell fragments, small stones) accumulate (Jones \& Jago 1993, Reise 2002). Vertically, the zone beyond the feeding funnel, where sediment slopes downwards to the feeding pocket, is considered to have a higher porosity and permeability (Jones \& Jago 1993, Riisgård \& Banta 1998). Following the modelling principle of Occam's Razor, we have chosen not to incorporate this heterogeneity. Instead, our aim is to investigate to what extent the first-order assumption of homogeneity can explain observations. Moreover, past discussions on the spatial variation of sediment properties within the Arenicola habitat were typically very qualitative and not supported by actual measurements. 
To our knowledge, no data are presently available on the porosity and permeability deviations within the permeable shell layer or the feeding funnel, nor are there any data on the extent of these zones. This absence of data is mainly because the corresponding porosity and permeability measurements would require a millimeter-scale resolution, and such resolution is presently not experimentally accessible (Rocha et al. 2005). Therefore, the inclusion of a more permeable shell layer and feeding funnel would extend the model by at least 4 unknown parameters, without any data constraint on these extra degrees of freedom. In the absence of such data, the assumption of homogeneity emerges as the most parsimonious starting point for model development.

\section{D flow model}

In a 3D setting, the resistance to flow in the sediment is described by the following generalised form of Darcy's law relating the velocity vector $\mathbf{v}_{\mathrm{d}}$ to the gradient of the pressure $p$ (Bear 1972, Bear \& Bachmat 1991).

$$
\mathbf{v}_{\mathrm{d}}=-\frac{k}{\mu}(\nabla p-\rho g \nabla z)
$$

where $\nabla \equiv[\partial / \partial x, \partial / \partial y, \partial / \partial z]$ is the gradient operator, $\mathbf{v}_{d}$ is the Darcy velocity vector, $k$ denotes the permeability of the sediment, $\mu$ is the dynamic viscosity of the pore water, $\rho$ is the density of the pore water, $g$ is the gravitational constant and $p$ is the pressure. The $z$-coordinate represents the depth measured downwards from the SWI. $\mathbf{v}_{\mathrm{d}}$ is related to the actual pore water velocity vector $\mathbf{v}$ such that $\mathbf{v}_{\mathrm{d}}=\phi \mathbf{v}$, where $\phi$ is the porosity. The density $\rho$ of the pore water is primarily dependent on temperature and salinity. Assuming an isothermal sediment and no salinity gradients, $\rho$ remains constant over the model domain, i.e. $\nabla \rho=0$. Under this condition, Darcy's law (Eq. 6) can be rewritten in the alternative form:

$$
\mathbf{v}_{\mathrm{d}}=-K \nabla H
$$

where $K=k \rho g / \mu$. Eq. (7) is the conventional presentation of Darcy's law in hydraulic problems. As noted above, it features $H=p / \rho g-z$ rather than $p$. Eq. (7) must be combined with the continuity equation for the incompressible pore water:

$$
\nabla \cdot \mathbf{v}_{\mathrm{d}}=0
$$

Direct substitution of Eq. (7) into Eq. (8) yields:

$$
\nabla \cdot(K \nabla H)=0
$$

Eq. (9) exemplifies the central role of $K$, or equally $k$, in the determination of flow patterns in the sediment. Note that Eq. (9) still allows the permeability to be spa- tially variable over the model domain. Given such a permeability 'heterogeneity', Eq. (9) calculates the spatial distribution of the hydraulic head, from which one can subsequently calculate the flow field via Eq. (7). As noted above, we consider the permeability of the sediment to be uniform over the Arenicola domain. Implementing this most parsimonious model assumption, Eq. (9) reduces to:

$$
\nabla^{2} H=0
$$

which is commonly referred to as the Laplace equation. The solution of this equation is a function $H(x, y, z)$ that describes the value of the hydraulic head at any point in the Arenicola domain. Via Eq. (7) one can subsequently calculate the associated flow pattern, i.e. the vector function $\mathbf{v}_{\mathrm{d}}(x, y, z)$.

\section{D boundary conditions}

A crucial step in the modelling process is the specification of proper boundary conditions. This task proves fairly straightforward for the external boundaries of the Arenicola domain. At the SWI we assume that pore water can freely flow out of the sediment. This is emulated by stating a constant hydraulic head condition (i.e. $H \equiv 0$ ) along this boundary. Laterally, we assume a full periodic coverage of the tidal flat by adjacent Arenicola domains. Consequently, at the boundary of 2 adjacent domains we impose a no-flux boundary condition (i.e. $\mathbf{v}_{\mathrm{d}} \times \mathbf{n} \equiv 0$, where $\mathbf{n}$ is the normal vector to the surface). Furthermore, it is assumed that advective flow does not penetrate the sediment below, and hence the same no-flux condition is also imposed at the domain's lower boundary.

The conditions specified at the internal boundaries of the Arenicola domain, i.e. along the shaft, the gallery and the feeding pocket, require more consideration. Firstly, the flow rate $Q$ pumped by the lugworm should leave the feeding pocket, and hence the following integral relation holds:

$$
Q=\int_{A_{\mathrm{fp}}} \mathbf{v}_{\mathrm{d}} \cdot \mathbf{n} \mathrm{d} A
$$

where $A_{\mathrm{fp}}$ denotes the surface area of the feeding pocket and $\mathbf{n}$ is the normal vector to this surface (pointing outwards). Two types of boundary conditions are possible along the feeding pocket. In theory, the lugworm imposes a constant pressure in excess over the hydrostatic pressure, resulting in a constant $H_{\text {fp }}$ along the surface of the feeding pocket. However, parameter values for this excess pressure are typically not available in the literature, and $Q$ is reported instead. So rather than imposing an isobaric surface, we assume that the discharge of water 
occurs uniformly over the surface of the feeding pocket. Eq. (11) then allows the calculation of the magnitude of $\mathbf{v}_{\mathrm{d}}$ normal to the surface of the feeding pocket for a given pumping rate $Q$, i.e. $\left\|\mathbf{v}_{\mathrm{d}}\right\|=Q / A_{\mathrm{fp}}$. Note that in the case of Arenicola, the distinction between uniform discharge and isobaric conditions along the feeding pocket is rather academic. Effectively, the feeding pocket constitutes a small void relative to its depth location in the sediment (i.e. $L_{\text {shaft }} / R_{\mathrm{fp}}>10$ ). Under such conditions, the feeding pocket becomes an isobaric surface, and hence both types of boundary conditions will produce the same flow pattern (this was verified by simulations, results not shown).

With regard to the conditions along the burrow wall, the gallery and the tail shaft need separate consideration. The gallery is where the worm remains while pumping. If the gallery were to have permeable walls, the lugworm's peristaltic pumping would be highly ineffective, as water forced between the body and the gallery's wall would immediately leak to the surrounding sediment, rendering the Arenicola pump utterly inefficient. Therefore, it seems a justifiable assumption to consider the gallery wall a noflux boundary. Yet, in the case of the tail shaft wall, it is not as clear a priori whether the walls should be considered open or closed to advective flow. In other words, the costs versus the benefits of insulating the tail shaft wall remain to be determined. To this end, we will explore 2 end-member cases, i.e. fully permeable and completely impermeable shaft walls. In the case of permeable walls, the pressure at the burrow wall is set to the hydrostatic pressure, neglecting the small pressure drop due to flow within the burrow. In the case of impermeable walls, the flow in the burrow is completely de-coupled from the flow in the surrounding sediment, i.e. no-flux boundary conditions along the complete burrow surface. For an illustration of both types of boundary conditions, see Fig. 5.

Eqs. (6) to (11) completely specify our model of pore water flow induced by lugworm bio-irrigation. Flow fields $\mathbf{v}_{\mathrm{d}}(x, y, z)$ over the Arenicola domain are obtained by numerical solution of this equation set for a suitable set of parameters. From such a flow field, one can construct the associated flow-line pattern, which consists of curves that are tangential to the velocity vector. All flow lines start from the feeding pocket, i.e. an isobaric surface at $H=H_{\mathrm{fp}}$, and arrive at the tail shaft or the SWI, i.e. an isobaric surface at $H \equiv 0$. Consequently, $\Delta H_{\mathrm{s}}=H_{\mathrm{fp}}$ and is the same for all flow lines. Effectively, the quantity $\Delta H_{\mathrm{s}}$ specifies the actual sediment resistance that the lugworm pump needs to overcome to maintain the flow rate (see Eq. 2).

\section{Influence of pumping rate and permeability on the flow pattern}

Even without actually solving the model, one can draw relevant conclusions with respect to lugworm bio-irrigation. By simple inspection of Eqs. (6) to (11), one can assess how crucial model parameters, such as $Q$ and $K$, will influence the flow field and flow-line pattern. Effectively, one can prove that both parameters will modulate the flow field without affecting the flow-line pattern. In other words, the adaptation of $Q$ or $K$ will cause a change in the magnitude, but not in the direction of $\mathbf{v}_{\mathrm{d}}$.

To show that a change in the lugworm's pumping rate does not affect the flow-line pattern, consider a certain lugworm that has created a particular burrow system and pumps at a particular flow rate $Q$. For these conditions, assume that the corresponding solution of the Laplace equation (Eq. 10) is given by the function $H(x, y, z)$, from which the flow field $\mathbf{v}_{\mathrm{d}}(x, y, z)$ and the associated flow-line pattern have been derived. Now assume that the lugworm remains within the same burrow system, but changes its pumping rate to a new value $Q^{*}$. In terms of the model, this comes down to an adaptation of the boundary condition (Eq. 11) along the feeding pocket. Due to the linearity of the Laplace equation, one can easily verify that the hydraulic head function $H^{*}=\left(Q^{*} / Q\right) H(x, y, z)$ forms a solution for this new set of boundary conditions. This relation also applies to the surface of the feeding pocket, and so we find that $H_{\mathrm{s}}^{*}=\left(Q^{*} / Q\right) H_{\mathrm{s}}$. In other words, when changing the pumping rate, the sediment resistance within the Arenicola domain will be proportionally rescaled:

$$
\frac{\Delta H_{\mathrm{s}}^{*}}{\Delta H_{\mathrm{s}}}=\frac{Q^{*}}{Q}
$$

Furthermore, due to the linearity of Darcy's law, the corresponding velocity field will also be rescaled by the same factor, i.e. $\mathbf{v}_{\mathrm{d}}^{*}=\left(Q^{*} / Q\right) \mathbf{v}_{\mathrm{d}}(x, y, z)$. This rescaling by a scalar factor changes the magnitude, but not the direction, of the velocity vector, and hence a change in the lugworm's pumping rate will not influence the flow-line pattern.

In a similar way, one can also show that a change in the hydraulic conductivity (or equally the permeability) does not affect the flow-line pattern. To this end, consider a certain sediment with hydraulic conductivity $K$, in which lugworms attain a certain density, construct a specific burrow system and maintain a given pumping rate $Q$. Again, assume that the corresponding solution of the Laplace equation (Eq. 10) is given by $H(x, y, z)$, while the associated velocity field becomes $\mathbf{v}_{\mathrm{d}}(x, y, z)$. Now consider a separate sediment environment with a different hydraulic conductivity $K^{*}$. Suppose that within this new environment lugworms 
adopt the same density, construct exactly the same burrow system and maintain the same pumping rate. In other words, neither the burrow geometry nor the pumping rate is affected by the texture of the sediment. Because the flow model (Eqs. 7 to 10) comprises a linear model with respect to the permeability, one can show that the hydraulic head function now becomes $H^{*}=\left(K / K^{*}\right) H(x, y, z)$. As a consequence, a decrease in the sediment permeability will lead to a proportional increase in the sediment resistance, governed by:

$$
\frac{\Delta H_{\mathrm{s}}^{*}}{\Delta H_{\mathrm{s}}}=\frac{K}{K^{*}}
$$

However, when implementing $H^{*}$ into Darcy's law (Eq. 9), one finds that the velocity field remains unchanged, i.e. $\mathbf{v}_{\mathrm{d}}^{*}=\mathbf{v}_{\mathrm{d}}(x, y, z)$. Effectively, when the lugworm is able to maintain a fixed pumping rate, a change in the sediment permeability does not affect the flow field, and hence the flow-line pattern remains unchanged as well. In reality, however, when the sediment resistance increases, the lugworm's pumping rate will decrease. In other words, one will observe a shift of the operation point of the lugworm pump, and the flow field will be modified (this scenario is examined below). However, the resulting change in the pumping rate will still not affect the flow-line pattern as shown in the discussion of Eq. (12).

\section{Linearity of the system characteristic}

The analysis of the previous section reveals that in the 3D pore water flow model, $\Delta H_{\mathrm{s}}$ is proportional to $Q$ (Eq. 12) and inversely proportional to $K$ (Eq. 13). Combining both propositions, we obtain:

$$
\Delta H_{\mathrm{s}}=\alpha_{3 \mathrm{D}} K^{-1} Q
$$

where $\alpha_{3 D}$ is a certain proportionality constant. Eq. (14) effectively confirms that also in the 3D case, Darcy's law leads to a linear system characteristic (Eq. 2) as was adopted earlier without proof. By comparing Eqs. (14) and (2), we obtain the following decomposition of the resistance coefficient:

$$
C_{f}=\alpha_{3 \mathrm{D}} K^{-1}
$$

The scaling factor $\alpha_{3 \mathrm{D}}$ designates the sensitivity of $C_{f}$ to changes in hydraulic conductivity. This proportionality constant is only dependent on those parameters that were kept invariant in the model analysis of the previous section. In other words, $\alpha_{3 D}$ only depends on the specific geometry of the Arenicola territory, which is determined by the lugworm density and the $3 \mathrm{D}$ geometry of the burrow. If one adopts the simplifying assumption that the shape of the Arenicola domain is not significantly affected by sediment type (i.e. the lugworm density and the burrow geometry do not depend on the permeability), the domain's resistance to flow scales inversely with the hydraulic conductivity.

The introduction of the geometrical factor $\alpha_{3 \mathrm{D}}$ via Eq. (15) ultimately results from the application of Darcy's law in 3 dimensions. As such, Eq. (15) forms the 3D counterpart of Eq. (5), which produces a very similar decomposition of $C_{f}$. The latter equation features the similar geometrical factor $\alpha_{1 \mathrm{D}}$ and results from the 1D application of Darcy's law. There is, however, a fundamental difference between Eq. (5) and Eq. (15). In the $1 \mathrm{D}$ approach, the value of $\alpha_{1 \mathrm{D}}$ needs to be fixed a priori. To this end, one requires a certain value for $A^{\mathrm{RPV}}$, which is a conceptual quantity that cannot be constrained by data. In contrast, in the 3D approach, the value of $\alpha_{3 \mathrm{D}}$ is obtained a posteriori from the model output. In other words, we can derive the appropriate values for $C_{f}$ and $\alpha_{3 \mathrm{D}}$ from the pressure and velocity fields that are simulated numerically.

To this end, we can take advantage of the linearity of the system characteristic (Eq. 14) to determine the operating point of the Arenicola pump for a specific Arenicola domain and a given hydraulic conductivity. This modelling procedure is illustrated in Fig. 3. First, $Q^{\max }=1.5 \mathrm{ml} \mathrm{min}^{-1}$ is imposed via the boundary condition (Eq. 11). The resulting pressure difference $\Delta H^{\text {sim }}$ between the SWI and the feeding pocket is obtained from the simulation output. Subsequently, the resistance coefficient is calculated as the slope of the linear system characteristic via:

$$
C_{f}=\frac{\Delta H^{\mathrm{sim}}}{Q^{\max }}
$$

Then, by substituting Eq. (16) into the quadratic equation (Eq. 3), the pumping rate $Q^{\mathrm{op}}$ at the operating point can be determined. Graphically (Fig. 3), this corresponds to finding the intersection point between the linear system characteristic (Eq. 2) with slope $C_{f}$ and the parabolic pump characteristic (Eq. 1).

\section{Numerical solution procedure}

Over the Arenicola domain, the Laplace equation (Eq. 9) is solved using a finite element approach implemented in the Chemical Engineering Module of FEM$\mathrm{LAB}^{\circledast}$. The simulation output consists of the steadystate field of the hydraulic head, the associated velocity field and the flow-line pattern. Fig. $2 \mathrm{~b}$ shows the unstructured finite element mesh used in the numerical simulations. Note that a finer mesh resolution is implemented near the burrow wall and the feeding pocket, since the largest pressure gradients occur in those zones. 


\section{SIMULATION RESULTS}

The above 3D modelling procedure was implemented to derive the system characteristic (i.e. to calculate $C_{f}$ ) for a representative Arenicola territory. Table 1 summarises the default parameter set used in the simulations, which reflects the ventilation activity of a standard Arenicola worm (sensu Riisgård et al. 1996) in a standard Arenicola domain (i.e. a territory with typical burrow at a typical lugworm density). The specification of this default parameter set is not in itself sufficient to constrain a solution. As noted before, the boundary conditions along the tail shaft part of the burrow need to be decided upon first. To this end, we simulated the flow patterns for both end-member conditions using the default parameter set. Subsequently, we used the default parameter set as the starting point for a sensitivity analysis with respect to sediment permeability.

\section{a}

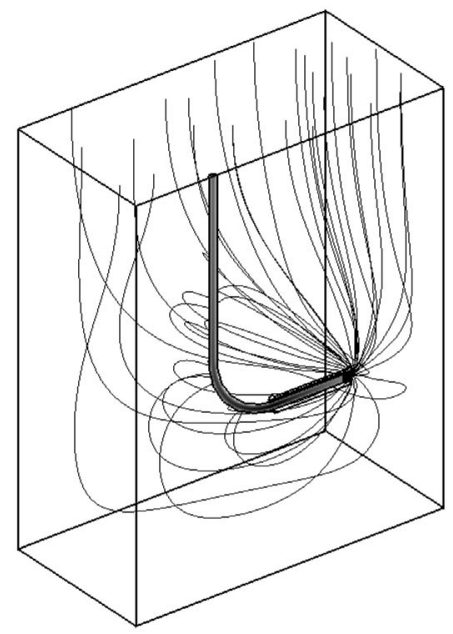

C

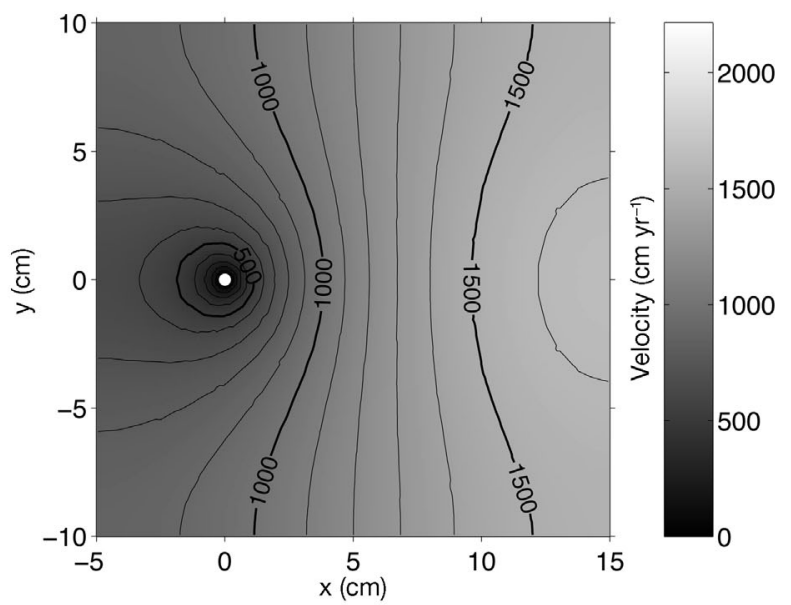

\section{Flow patterns}

Flow patterns are obtained for both the case in which the tail shaft walls are permeable to advective flow (Fig. 4a) and for the case of fully insulated (i.e. nonpermeable) shaft walls (Fig. 4b). Similar in both scenarios is the clear 3D nature of the flow pattern. Flow lines irradiate from the feeding pocket, and, while diverging, these flow lines rise to the sediment surface over an increasingly large area. This pattern deviates significantly from the classical 1D representation (Benoit et al. 1991, Timmermann et al. 2002, 2003), which assumes a percolation column of constant crosssection, through which the burrow water migrates upwards along parallel flow lines. A second striking feature in Fig. 4 is that flow lines also head downwards from the injection point. This implies that a zone underneath the burrow will also be flushed. In other words, the sediment below the feeding depth is not

b
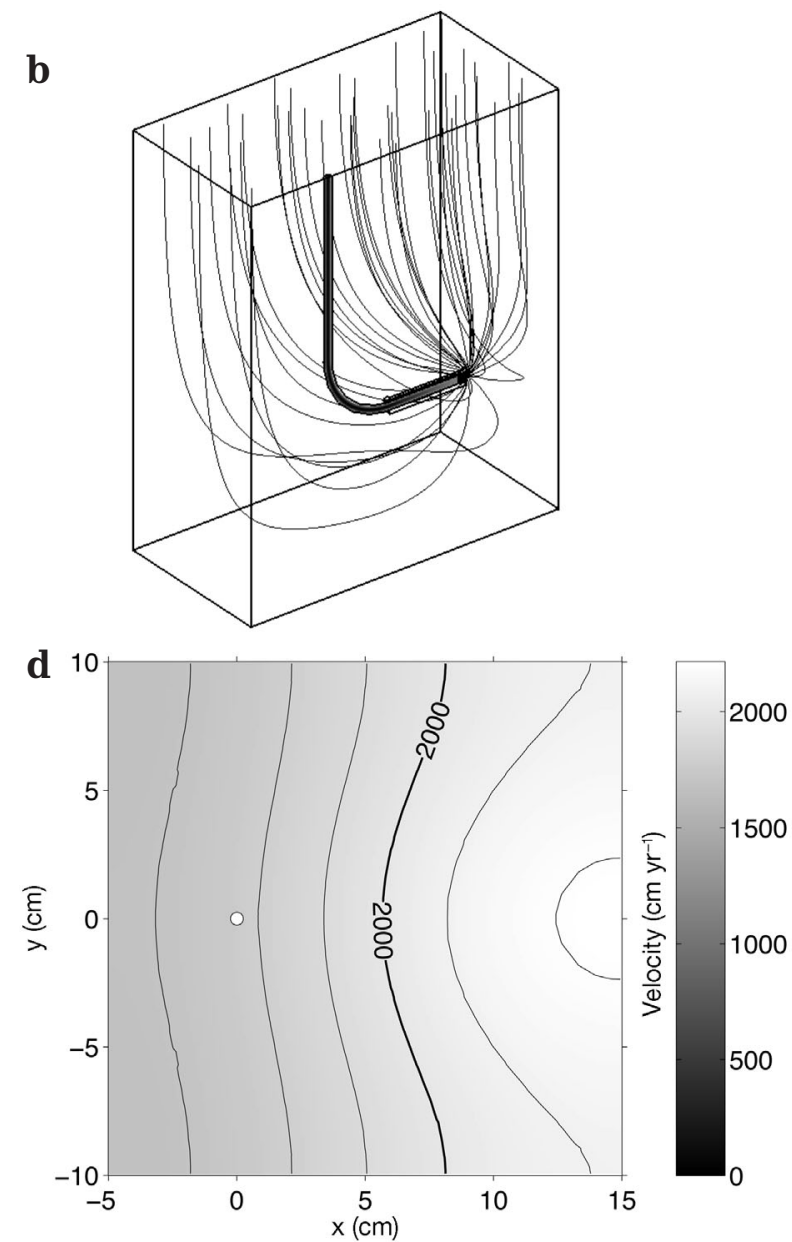

Fig. 4. Simulated flow-line patterns for a standard Arenicola domain (parameter set in Table 1). (a) Flow lines short-circuit back to the burrow when the burrow walls are open to advective flow. (b) Flow lines rise parallel to the sediment surface pattern when the burrow walls are impermeable to advective flow. $(c, d)$ Patterns of the pore water velocity perpendicular to the sedimentwater interface corresponding to the simulations $(a, b)$. The plot mimics an aerial view of the sediment surface 
only affected by diffusive transport, but also by advection, i.e. by bulk pore water flow. This aspect is not accounted for in the conventional 1D modelling approach to burrow water injection.

In addition to similarities, Fig. 4 also shows some striking differences between the 2 end-members of shaft wall permeability. In the case of permeable burrow walls (Fig. 4a), some flow lines curve back to the burrow wall. This implies that a certain amount of the water pumped by the lugworm effectively re-enters the burrow. Integrating this advective flux, our simulations show that the return flow of anoxic pore water consititutes $40 \%$ of the total pumping rate (Fig. 5a). Conversely, in the case of impermeable burrow walls (Fig. 4b), all flow lines eventually 'line up' in parallel and arrive at the sediment-water surface, since in this scenario it is the only boundary open to flow (Fig. 5b). So, the flow-line pattern now consists of 2 separate zones: (1) a lower 'irradiation' zone (heterogeneous, 3D), where flow lines irradiate from the feeding pocket, and (2) an upper 'percolation' zone (homogeneous, 1D), where flow lines align in parallel to the vertical. Effectively, the conventional 1D approach (Benoit et al. 1991, Timmermann et al. 2002, 2003) assumes that the lower 3D irradiation zone is negligibly small as compared to the upper 1D percolation zone. However, our simulations show that both zones are of the same extent. Consequently, in order to represent the irradiation zone in a $1 \mathrm{D}$ reactive transport

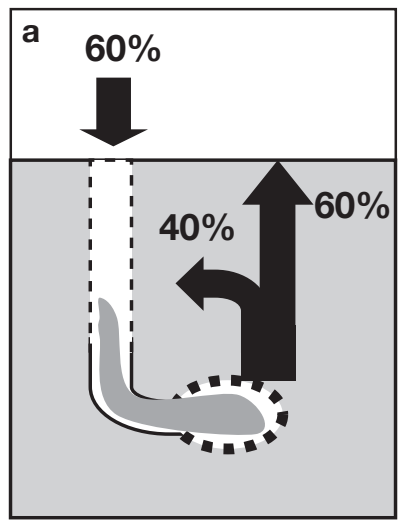

Permeable burrow walls
Impermeable burrow walls

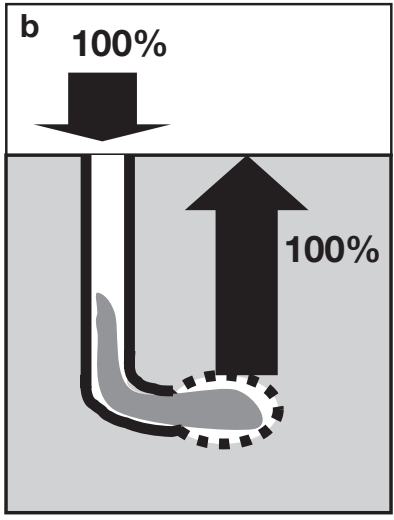

Fig. 5. Dependence of the sediment irrigation pattern on the boundary conditions at the burrow walls (solid lines, boundaries are closed to flow; dashed lines, boundaries are open to flow). (a) When the tail shaft wall is open to flow, the return flow of anoxic pore water constitutes $40 \%$ of the total pumping rate. Only $60 \%$ of the burrow water flow is derived as fresh oxygenated water from the overlying water column. (b) When the tail shaft wall is closed to flow, no return flow to the burrow exists. All irrigated pore water eventually crosses the sediment-water interface, and all burrow water originates from the overlying water column model, one needs to take account of an appropriate mapping of the 3D advective transport within this zone in a $1 \mathrm{D}$ model formulation.

The difference between the 2 flow scenarios is also evident from the velocity field at the SWI (Fig. 4c,d). In the case of permeable burrow walls, there are distinct gradients in velocity at the SWI (Fig. 4c). Velocities are higher in the area above the feeding pocket, indicative of an increased upwards percolation in this zone. Around the entrance to the burrow, velocities are low. When burrow walls are open to advective flow, the burrow acts as a sink, and so velocity vectors are normally oriented to the burrow surface. Accordingly, the vertical component of the velocity vectors at the SWI vanishes when approaching the burrow entrance. In contrast, for the case of impermeable burrow walls, the flow across the SWI is almost uniform over the domain (Fig. 4d), with a Darcy velocity of around $2000 \mathrm{~cm} \mathrm{yr}^{-1}$. This is indeed the expected average velocity, obtained when dividing the lugworm's yearly pumping rate, i.e. $Q^{\max } \times 24 \times 365=7.9 \times 10^{5} \mathrm{~cm}^{3} \mathrm{yr}^{-1}$, by the surface area of the Arenicola domain, i.e. $400 \mathrm{~cm}^{2}$. Note that the effective velocity in the pore water is higher, i.e. $\mathbf{v}_{\mathrm{SWI}} \approx$ $4000 \mathrm{~cm} \mathrm{yr}^{-1}$ (the Darcy velocity must be divided by the porosity). These velocity values are 3 orders of magnitude higher than those in muddy sediments (Boudreau 1997), but similar to those observed in groundwater transport (Bear 1972, Freeze \& Cherry 1979). Assuming an irrigated zone of $20 \mathrm{~cm}$, i.e. irrigation extends to $5 \mathrm{~cm}$ below the feeding depth, the frequency at which the lugworm flushes the pore water becomes $200 \mathrm{yr}^{-1}$. This results in an average residence time of $<2 \mathrm{~d}$ for the pore water within the bio-irrigated zone. Such high flushing rates have a considerable impact on the biogeochemistry of the sediment (Huettel 1990, Banta et al. 1998).

\section{Sensitivity to permeability}

We used the above simulation procedure to determine the operation point of the Arenicola pump for different sediment types (Table 2, Fig. 6). To this end, we varied the permeability, while all other parameters retained the value of the default parameter set (Table 1). The selected permeability range is characteristic for Arenicola habitat, i.e. from clean, coarse sand $\left(k=2.5 \times 10^{-11} \mathrm{~m}^{2}\right)$ to silty, fine sand $(k=1.0 \times$ $10^{-13} \mathrm{~m}^{2}$ ). Simulations were performed for both endmember conditions of burrow wall permeability, but only results for impermeable burrows are shown. Remarkably, $C_{f \prime}$ and hence the lugworm's operating point, did not significantly depend on the type of boundary condition employed at the tail shaft wall. To explain this, we need to analyse where the actual resistance to flow occurs in the Arenicola domain. Pressure 
Table 2. Simulation results for a range of sediment permeabilities

\begin{tabular}{|lcccccc|}
\hline Permeability & $k$ & $\mathrm{~m}^{2}$ & $2.5 \times 10^{-11}$ & $1.0 \times 10^{-11}$ & $1.0 \times 10^{-12}$ & $1.0 \times 10^{-13}$ \\
Hydraulic conductivity & $K$ & $\mathrm{~m} \mathrm{~s}^{-1}$ & $2.46 \times 10^{-4}$ & $9.82 \times 10^{-5}$ & $9.82 \times 10^{-6}$ & $9.82 \times 10^{-7}$ \\
Simulated pressure & $\Delta H^{\mathrm{sim}}$ & $\mathrm{cm} \mathrm{H}_{2} \mathrm{O}$ & 0.93 & 2.24 & 13.5 & 19.9 \\
Frictional resistance coefficient & $C_{f}$ & $\mathrm{~cm}^{-2} \mathrm{~min}$ & 0.63 & 1.58 & 15.8 & 158 \\
Flow at operation point & $Q^{\mathrm{op}}$ & $\mathrm{cm}^{3} \mathrm{~min}^{-1}$ & 1.47 & 1.41 & 0.85 & 0.13 \\
Scaling factor & $\alpha_{3 \mathrm{D}}$ & $\mathrm{cm}^{-1}$ & 0.93 & 0.93 & 0.93 & 0.93 \\
Representative percolation area & $A^{\mathrm{RPV}}$ & $\mathrm{cm}^{2}$ & 16.0 & 16.1 & 16.1 & 16.2 \\
\hline
\end{tabular}

distribution plots (results not shown) reveal that the highest pressure gradients occur close to the feeding pocket. These same plots also show that pressure gradients quickly drop when moving away from the feeding pocket. This implies that the resistance to flow is predominantly concentrated in a relatively small zone around the feeding pocket. In other words, the irradiation zone centralises almost all resistance, while the percolation zone does not significantly influence the overall resistance. As this irradiation zone is very similar in both situations (only the percolation zone is different), the overall sediment resistance is very similar. This explains the insensitivity of $C_{f}$ with respect to the boundary condition at the shaft wall.

As expected, $Q^{\text {op }}$ decreases with decreasing $K$ (Fig. 6a). An increase of the intrinsic sediment resistance (lower $K$ values) shifts the operation point of the lugworm pump to lower pumping rates (lower $Q^{\mathrm{op}}$ values). However, the relation between these variables shows 2 specific trends. Below a threshold value of $K=$ $1.0 \times 10^{-4} \mathrm{~m} \mathrm{~s}^{-1}$, the operational pumping rate decreases with the logarithm of the hydraulic conductivity. So decreasing the sediment's permeability will markedly in- fluence the operation point of the lugworm pump. For example, at a value around $K=1.0 \times 10^{-5} \mathrm{~m} \mathrm{~s}^{-1}$, the operational pumping rate only attains $50 \%$ of the maximal pumping rate (Fig. 6a). Yet, above a threshold hydraulic conductivity of $K=1.0 \times 10^{-4} \mathrm{~m} \mathrm{~s}^{-1}$, the operational flux does not increase any longer and almost equals the maximal pumping rate. Accordingly, any further increase of the sediment permeability will no longer influence the operation point of the lugworm pump.

\section{Representative percolation area}

As noted above, the classical 1D approach is based on the specification of a so-called 'representative 1D percolation volume', characterised by the geometrical constant $\alpha_{1 \mathrm{D}}$. An important problem was that $\alpha_{1 \mathrm{D}}$ needed $a$ priori specification, and hence required the debatable determination of $A^{\mathrm{RPV}}$. This arbitrariness in the specification of the representative percolation volume can now be removed. Eq. (15) predicts that, for a fixed model geometry and a fixed pumping rate, $C_{f}$ should linearly scale with the inverse of $K$. Our numer-
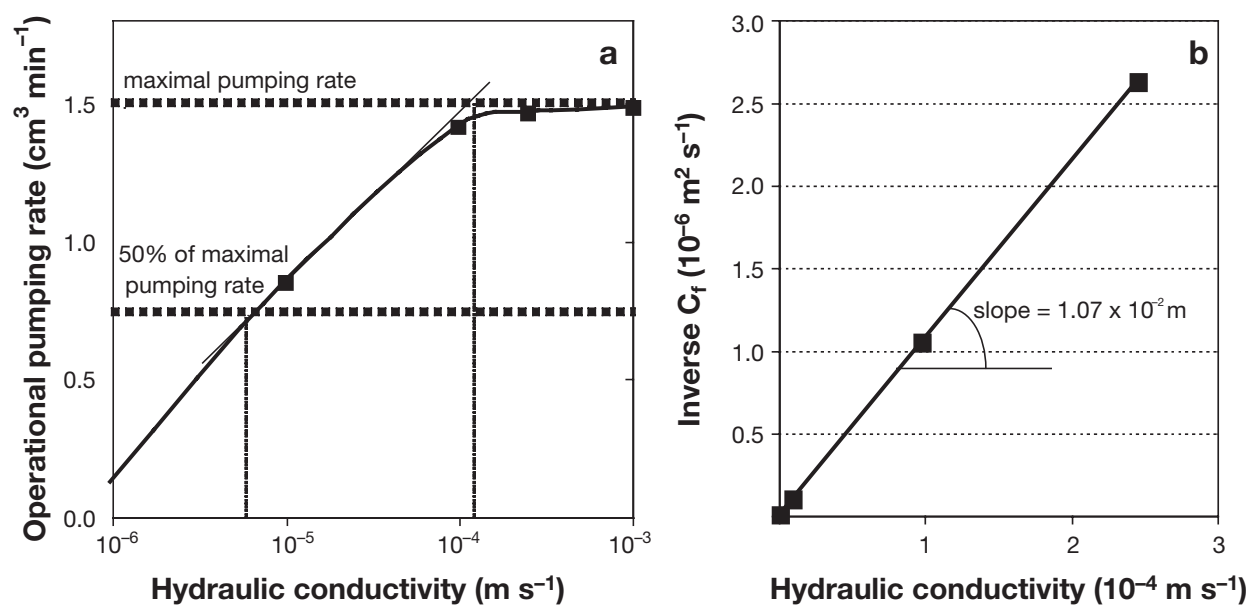

Fig. 6. Dependence of the operation point of the lugworm pump on the hydraulic conductivity of the sediment: summary of model results. (a) Below $K=1 \times 10^{-4} \mathrm{~m} \mathrm{~s}^{-1}$ the operational pumping rate scales with the logarithm of the hydraulic conductivity. Above $K=1 \times 10^{-4} \mathrm{~m} \mathrm{~s}^{-1}$ the operational pumping rate remains roughly invariant with the hydraulic conductivity. (b) The inverse of the frictional resistance of the sediment scales linearly with hydraulic conductivity as predicted by theory 
ical simulations corroborate this theoretical relationship, as shown in Fig. $6 \mathrm{~b}$, which plots $C_{f}^{-1}$ as a function of $K$. The scaling factor $\alpha_{3 \mathrm{D}}$ can be calculated by taking the inverse of the slope of this graph and using the proper unit conversion. We obtained the value of $0.93 \mathrm{~cm}^{-1}$ for our standard Arenicola domain (Fig. 6b, Table 2). As discussed above, this value of $\alpha_{3 \mathrm{D}}$ is not dependent on the permeability of the sediment (Table 2 ). By setting $\alpha_{1 \mathrm{D}}$ to the value calculated for $\alpha_{3 \mathrm{D}}$ from the model, we effectively map the (real) 3D flow pattern into a corresponding (virtual) 1D flow pattern that has the same resistance to flow. This way, using Eq. (5), it becomes possible to quantify the cross-sectional area of this representative 1D percolation volume as:

$$
A^{\mathrm{RPV}}=\frac{L_{\text {shaft }}}{\alpha_{3 \mathrm{D}}}=\frac{L_{\text {shaft }}}{C_{f} K}
$$

where $L_{\text {shaft }}$ is the tail shaft length, i.e. the depth of gallery and feeding pocket. For the standard Arenicola domain employed in our simulations (Table 1), we obtained $A^{\mathrm{RPV}}=16 \mathrm{~cm}^{2}$, implying a representative percolation column of $4.5 \mathrm{~cm}$ in diameter (Table 2). This value for $A^{\mathrm{RPV}}$ deviates markedly from the value of 5.5 $\mathrm{cm}^{2}$ postulated in Riisgård et al. (1996). Yet, it lies within the range of 5.5 to $29 \mathrm{~cm}^{2}$ obtained from fitting a 1D injection model to $\mathrm{Br}^{-}$profiles, as reported by Timmermann et al. (2002).

\section{Influence of quicksand column}

The value of $A^{\mathrm{RPV}}$ is obtained for an Arenicola domain with a uniform permeability. However, in the field, observations indicate that lugworms create a so-called 'quicksand column', i.e. a loosened cylinder sediment that is assumed to have a significantly higher permeability (Jakobsen 1967, Rijken 1979, Retraubun et al. 1996). In this view, the quicksand column may act as a 'pore water highway', i.e. a zone of high permeability that channels and facilitates the upward flow of pore water. In a qualitative sense, one can expect that the inclusion of the quicksand column will result in a concentration of flow lines and a reduction in the value of $A^{\mathrm{RPV}}$ in Eq. (17). Provided one has a description of the associated spatial variation in permeability, one could consider the quicksand column as part of the Arenicola domain and investigate its influence on the pore water flow pattern using the modelling approach as outlined above. As discussed above, this was not done here, but is scheduled to be included in a further sensitivity analysis of the model.

However, Eq. (17) does allow a crude estimate of the influence of the quicksand column on the overall permeability. To this end, one can assume a representative 1D percolation zone with 2 concentric zones, i.e. an outer zone of bulk sediment (BS) and an inner quicksand column (QC). Applying the theory of parallel resistances, the apparent conductivity $K^{\text {app }}$ of this heterogeneous percolation zone can be calculated as:

$$
\frac{K^{\mathrm{app}}}{K^{\mathrm{BS}}}=\frac{A^{\mathrm{QC}}}{A^{\mathrm{RPV}}} \xi+\left(1-\frac{A^{\mathrm{QC}}}{A^{\mathrm{RPV}}}\right)
$$

where $A^{\mathrm{RPV}}$ is the cross-sectional area of the percolation zone and $K^{\mathrm{BS}}$ is the hydraulic conductivity of the bulk sediment. Furthermore, $A^{\mathrm{QC}}$ is the cross-sectional area of the quicksand column, and $\xi=K^{\mathrm{QC}} / K^{\mathrm{BS}}$ represents the relative enhancement of the permeability within this column $(\xi>1)$. At present, both parameters $A^{\mathrm{QC}}$ and $\xi$ are poorly constrained by data. For the diameter of the quicksand column, we only found a value of $5 \mathrm{~mm}$, as reported by Rijken (1979), which was derived from tracer experiments with glass beads. For $\xi$, we did not retrieve any information. However, considering a 10 -fold increase in the permeability and using the value of $16 \mathrm{~cm}^{2}$ for $A^{\mathrm{RPV}}$ as derived above, Eq. (18) leads to a factor of 1.44. In other words, the presence of the quicksand column enhances the apparent hydraulic conductivity of the sediment by $44 \%$. Because the hydraulic conductivity in natural sediments effectively varies over several orders of magnitude (Freeze \& Cherry 1979), i.e. from $10^{-10} \mathrm{~m} \mathrm{~s}^{-1}$ (marine clay) to $10^{-2} \mathrm{~m} \mathrm{~s}^{-1}$ (clean coarse sand), a 1.44 increase due to the presence of the quicksand column is a rather small effect. In other words, one requires wider columns, with higher enhancement factors $(\xi)$ to substantially influence the bulk permeability.

\section{ECOLOGICAL IMPLICATIONS}

\section{Permeability of burrow walls}

Our model simulations show that a reduction of the advective flow through the burrow wall provides a clear ecological advantage for the lugworm. Hydrodynamic insulation of the burrow walls prevents the short-circuiting of flow lines, and thus shuns the inflow of pore water into the burrow. Without this insulation, $40 \%$ of the burrow water is derived from pore water and only $60 \%$ originates from the overlying water column (Fig. 5a). Obviously, such recirculation would have an adverse effect on the oxygen supply to the lugworm. According to Zebe \& Schiedek (1996) Arenicola marina is able to extract between 32 and $40 \%$ of the oxygen under natural conditions. Once injected into the sediment, the remaining oxygen is rapidly consumed by the microbial community, and hence any water re-entering the burrow will be anoxic. Assuming that oxygen uptake is a function of the concentration difference across the gill surface, this dilution of fresh overlying water with anoxic pore water will reduce the 
lugworm's oxygen intake by $40 \%$. In other words, the lugworm would have to increase its pumping rate by a factor of 1.67 to obtain the same oxygen supply.

Two mechanisms can be envisaged to prevent this re-entrance of anoxic pore water, i.e. active and passive burrow insulation. In the case of active insulation, the lugworm will invest resources to reduce the advective inflow of pore water into its burrow. Obviously, from an evolutionary perspective, the benefits of this investment in terms of enhanced oxygen supply have to outweigh the costs. In the passive case, no additional resources are invested, and the decreased burrow wall permeability simply originates as a side-effect of burrow ventilation activity.

There are indications that 2 types of active insulation might be operating, i.e. the lining of burrow walls with mucus and the mechanical re-enforcement of burrow walls. In muddy sediments, organic burrow linings have been shown to reduce the diffusive permeability of burrow walls, so that diffusion coefficients are only 10 to $40 \%$ of their corresponding value in free solution (Aller 1983). Accordingly, one might expect similar adaptations to reduce the advective flow through burrow linings in permeable sediments. Evidence of active burrow insulation has been reported by Huettel (1990), who observed that sediment particles in the burrow wall of the tail shaft are tightly cemented by mucus. This mucus layer was estimated to be about $1 \mathrm{~mm}$ thick and relatively impermeable for the advective flow of pore water. Furthermore, Atkinson \& Nash (1990) observed that Callianassa subterranea produces a mucus lining when burrowing in sandy sediments, but not in muddy environments. It was argued that this lining provided structural stability in the less cohesive sandy substrate. However, our link between oxygen supply and wall permeability provides an additional explanation for this observation.

Mechanical hardening might be a second way to actively decrease the permeability of the burrow wall. The case for this type of insulation is significantly strengthened by recent observations on intertidal sediments with a novel acoustic technique (S. A. Woodin unpubl. data). Pressure sensors were placed in situ in the vicinity of burrows of Abarenicola pacifica, a related arenicolid polychaete with a similar ecology. Large-amplitude infrasound signals were monitored that are associated with macrofaunal activity. A striking pattern of pressure pulses was recorded in a limited time span just after burrow construction. Closer inspection revealed that this signal was associated with 'head banging' behaviour, i.e. hammering mucus and sediment grains tightly together in the burrow wall.

In addition to active insulation, plentiful evidence of authigenic mineral formation near Arenicola burrows (Gribsholt \& Kristensen 2003, Nielsen et al. 2003) indi- cates that passive insulation might be operational as well. The transfer of oxygen across the burrow wall typically creates a 2 to $4 \mathrm{~mm}$ thick brownish crust around the tail shaft, associated with the precipitation of ferric (hydr)oxides (Reise 1985, Huettel 1990). Deeper in the sediment and around the gallery the colour of this halo may change to grey, associated with pyrite formation (Huettel 1990). Such authigenic mineral formation $(\mathrm{FeOOH}, \mathrm{FeS})$ may result in pore cementation and a reduced permeability near the burrow wall. However, it remains to be determined to what extent authigenic mineral formation effectively changes the permeability of the burrow wall.

\section{Distribution of Arenicola marina}

Surveys on the distribution of $A$. marina typically reveal the same general pattern with particle size: the lugworm is absent in fine mud, abundant in fine and muddy sand and absent from coarse sand and gravel (Longbottom 1970). The absence of lugworms from coarse sand is attributed to insufficient food, since under exceptional conditions lugworms have been found in these environments, e.g. a coarse sand exposed to sewage outflow (Longbottom 1970). The absence of lugworms from fine mud has been explained by the inability to maintain a permanent burrow in such a 'liquid' environment (Longbottom 1970). The latter argument is rather unconvincing for a number of reasons. (1) Other benthic macrofauna are able to create (semi) permanent burrows in muddy environments. (2) As discussed above, lugworms have been shown to exhibit adaptations (mucus production, head banging) that fortify burrow structures.

Our model analysis of burrow ventilation activity, however, offers an alternative explanation (Fig. 7). The physics of pore water advection causes burrow ventilation to become energetically costly at low sediment permeabilities. To show this, we have first quantified the resistance to pore water flow in a representative Arenicola territory, as expressed by $C_{f}$. In a second step, we have evaluated $C_{f}$ as a function of the sediment permeability. As summarised in Fig. 7, the sediment permeability constitutes a major factor controlling the lugworm's pumping rate. Lower permeabilities will increase $C_{f}$ and shift the operation point of the Arenicola pump to a lower operational pumping rate. Accordingly, the lugworm will require higher pumping pressures, and hence an increased energy expenditure, to maintain the same burrow water flow and the same oxygen supply. One can imagine that when the permeability falls below a certain threshold, Arenicola's operating point will shift to a pumping rate too low to ensure its oxygen supply. Assuming (1) that 


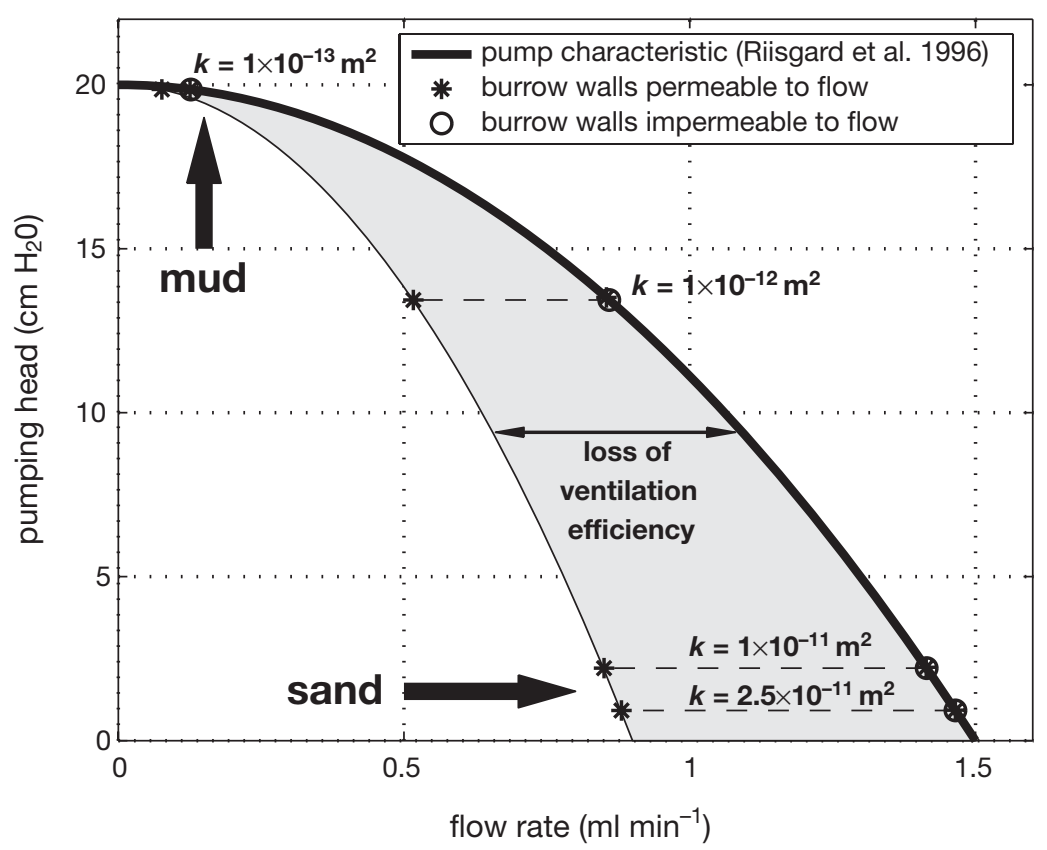

Fig. 7. Oxygen supply as a function of sediment permeability. In the case of impermeable burrow walls, the oxygen supply simply scales with the pumping rate. When burrow walls are open to advective flow, anoxic flow short-circuiting occurs and the oxygen supply is reduced by about $40 \%$ (marked as the 'loss of ventilation efficiency'). The 'effective' operation point of the lugworm pump, expressed in terms of oxygen supply, now lies on an effective 'pump characteristic', which depicts a lower apparent flow rate for the same pumping head

grain size distribution has not changed in the microcosms). In situ, Jones \& Jago (1993) reported a decrease in the electrical resistivity of the sediment with an increasing density of lugworm burrows. This decrease was then linked to an increase in the porosity, and, by inference, to an increase in permeability. However, the link between porosity and permeability is typically non-linear and highly dependent on the grain size distribution.

Furthermore, permeability may not increase throughout the whole Arenicola territory, but can be due to strong localised enhancements. In this regard, one could think of the lugworm as creating a 'pore water highway', i.e. a zone of high permeability that channels and facilitates the upward flow of pore water. It has been suggested that the quicksand column fulfils this task (Jakobsen 1967, Rijken 1979, Retraubun et al. 1996). Within this cylinder, loosened sediment slides from the sediment surface down to the feeding pocket. However, our preliminary calculations indicate that in order to sub-

\section{A. marina respiration reduces the oxygen concentra-} tion in the burrow water by about $40 \%$ (Zebe \& Schiedek 1996) and (2) that oxygen uptake becomes critical at $10 \%$ oxygen saturation, the oxygen supply becomes critical at $50 \%$ of its normal value. Consequently, allowing a $50 \%$ reduction from $Q^{\max }$, we estimated the critical permeability to be $10^{-12} \mathrm{~m}^{2}$ for our standard Arenicola domain (Fig. 7). In terms of median grain size, this critical permeability is roughly associated with the transition from muddy sand (Arenicola present) to fine mud (Arenicola absent).

The strong link between permeability and oxygen availability also implies that there is a clear scope for habitat improvement. This can be done in 2 ways: either affecting the bulk permeability throughout the territory, or creating local zones of high permeability. Our model simulations indicate that by increasing the bulk permeability of its territory, the lugworm could clearly improve its ventilation efficiency and hence reduce the energetic cost of its oxygen supply. However, at present, the data to corroborate this model hypothesis are few and indirect. In microcosm experiments with Arenicola marina, Kure \& Forbes (1997) observed a significant increase of the porosity after $36 \mathrm{~h}$. Although permeability was not quantified, one might expect a corresponding increase in the permeability in the microcosm sediment (assuming that the stantially influence the overall sediment permeability, one requires substantially wider pore water highways than the quicksand columns of $5 \mathrm{~mm}$ diameter that have been observed in the field (Rijken 1979). Accordingly, direct (and preferably in situ) measurements of permeability are needed to confirm the occurrence and elucidate the nature (local or bulk) of habitat improvement through permeability modulation.

\section{CONCLUSION}

We have presented a modelling procedure that illustrates how physical constraints of the environment interact with the way benthic fauna ventilate their burrows. This model analysis was used to explain existing observations on the distribution and behavioural adaptations of Arenicola marina, as well as to put forward new hypotheses with regard to lugworm ecology. Most of all, our simulations show that permeability exerts an important control on the lugworm's ventilation activity, creating an opportunity for active habitat improvement. This can occur in 2 distinct ways. Firstly, the lugworm has a clear ecological advantage in reducing the permeability of its burrow walls. Without such insulation, flow lines short-circuit from the feeding pocket to the burrow, resulting in a $40 \%$ dilution of the burrow 
water with anoxic pore water. Secondly, it is clearly advantageous for the lugworm to increase the permeability of its habitat. When the permeability increases, the sediment resistance decreases, and, hence, the lugworm needs to overcome a decreased back pressure to maintain the same ventilation rate and oxygen supply.

The modelling approach presented here is not limited to the specific case of Arenicola marina. It applies to a general 3D sediment territory given that boundary conditions are sufficiently similar. In other words, it can also be used to analyse the bio-irrigational activity of other organisms, provided that burrow ventilation is coupled to advective flows in the sediments. Extending our conclusions from the lugworm to other burrowventilating macrofauna, we can claim that sediment permeability is an important ecological parameter in sandy sediment ecosystems. This conclusion markedly contrasts with the current practice in macrofauna field studies. Unlike other geological parameters, such as grain size distribution and porosity, benthic studies usually do not quantify sediment permeability as an environmental factor.

Acknowledgements. This research was supported by grants from the EU (NAME project, EVK\#3-CT-2001-00066, COSA project, EVK\#3-CT-2002-00076) and a PIONIER grant from the Netherlands Organisation for Scientific Research (NWO, 833.02.2002). This is Publication 3497 of the NIOO-KNAW (Netherlands Institute of Ecology).

\section{LITERATURE CITED}

Aller RC (1980) Quantifying solute distributions in the bioturbated zone of marine sediments by defining an average micro-environment. Geochim Cosmochim Acta 44: 1955-1965

Aller RC (1983) The importance of the diffusive permeability of animal burrow linings in determining marine sediment chemistry. J Mar Res 41:299-322

Aller RC (2001) Transport and reactions in the bioirrigated zone. In: Boudreau BP, Jørgensen BB (eds) The benthic boundary layer. Oxford University Press, Oxford

Atkinson RJA, Nash RDM (1990) Some preliminary observations on the burrows of Callianassa subterranea (Montagu) from the west coast of Scotland. J Nat Hist 24:403-413

Banta GT, Holmer M, Jensen MH, Kristensen E (1999) Effects of two polychaete worms, Nereis diversicolor and Arenicola marina, on aerobic and anaerobic decomposition in a sandy marine sediment. Aquat Microb Ecol 19:189-204

Baumfalk YA (1979) On the pumping activity of Arenicola marina. Neth J Sea Res 13:422-427

Bear J (1972) Dynamics of fluids in porous media. Elsevier, New York

Bear J, Bachmat Y (1991) Introduction to modeling of transport phenomena in porous media. Kluwer Academic Publishers, Dordrecht

Benoit JM, Torgersen T, Odonnell J (1991) An advection-diffusion model for Rn-222 transport in near-shore sediments inhabited by sedentary polychaetes. Earth and Planetary Science Letters 105:463-473
Beukema JJ, De Vlas J (1979) Population parameters of the lugworm, Arenicola marina, living on tidal flats in the Dutch Wadden Sea. Neth J Sea Res 13:331-353

Boudreau BP (1997) Diagenetic models and their implementation. Springer, Berlin

Cadee GC (1976) Sediment reworking by Arenicola marina on tidal flats in the Dutch Wadden Sea. Neth J Sea Res 10: $440-460$

Forster S, Graf G (1995) Impact of irrigation on oxygen flux into the sediment: intermittent pumping by Callianassa subterranea and 'piston-pumping' by Lanice conchilega. Mar Biol 123:335-346

Foster-Smith RL (1978) An analysis of water flow in tubeliving animals. J Exp Mar Biol Ecol 34:73-95

Freeze RA, Cherry JA (1979) Groundwater. Prentice-Hall, Englewood Cliffs, NJ

Gribsholt B, Kristensen E (2003) Benthic metabolism and sulfur cycling along an inundation gradient in a tidal Spartina anglica salt marsh. Limnol Oceanogr 48:2151-2162

Gust G, Harisson JT (1981) Biological pumps at the sediment-water interface: mechanistic evaluation of the alpheid shrimp Alpheus mackayi and its irrigation pattern. Mar Biol 64:71-78

Herman PMJ, Middelburg JJ, Van De Koppel J, Heip CHR (1999) Ecology of estuarine macrobenthos. Adv Ecol Res 29:195-240

Huettel M (1990) Influence of the lugworm Arenicola marina on porewater nutrient profiles of sand flat sediments. Mar Ecol Prog Ser 62:241-248

Jakobsen VH (1967) The feeding of the lugworm Arenicola marina L. Ophelia 4:91-109

Jones CG, Lawton JH, Shachak M (1994) Organisms as ecosystem engineers. Oikos 69:373-386

Jones SE, Jago CF (1993) In situ assessment of modification of sediment properties by burrowing invertebrates. Mar Biol 115:133-142

Koretsky CM, Meile C, Van Cappellen P (2002) Quantifying bioirrigation using ecological parameters: a stochastic approach. Geochem Trans 3:17-30

Kristensen E (2001) Impact of polychaetes (Nereis spp. and Arenicola marina) on carbon biogeochemistry in coastal marine sediments. Geochem Trans 2:92-103

Kruger F (1959) Zur Ernährungsphysiologie von Arenicola marina (L.). Zool Anz 22:115-120

Kruger F (1971) Bau und Leben des Wattwurmes Arenicola marina. Helgol Meeresunters 22:149-200

Kure LK, Forbes TL (1997) Impact of bioturbation by Arenicola marina on the fate of particle-bound fluoroanthene. Mar Ecol Prog Ser 156:157-166

Levinton J (1995) Bioturbators as ecosystem engineers: control of the sediment fabric, inter-individual interactions, and material fluxes. In: Jones CG, Lawton JH (eds) Linking species and ecosystems. Chapman and Hall, New York

Longbottom MR (1970) The distribution of Arenicola marina (L.) with particular reference to the effects of particle size and organic matter of the sediments. J Exp Mar Biol Ecol 5:138-157

Meadows PS, Tait J (1989) Modification of sediment permeability and shear-strength by two burrowing invertebrates. Mar Biol 101:75-82

Meile C, Van Cappellen P (2003) Global estimates of enhanced solute transport in marine sediments. Limnol Oceanogr 48:777-786

Murray JMH, Meadows A, Meadows PS (2002) Biogeomorphological implications of microscale interactions between sediment geotechnics and marine benthos: a review. Geomorphology 47:15-30 
Nielsen OI, Kristensen E, Holmer M (2003) Impact of Arenicola marina (Polychaeta) on sediment sulfur dynamics. Aquat Microb Ecol 33:95-105

Reise K (1985) Tidal flat ecology. Springer, Berlin

Reise K (2002) Sediment mediated species interactions in coastal waters. J Sea Res 48:127-141

Retraubun ASW, Dawson M, Evans SM (1996) The role of the burrow funnel in feeding processes in the lugworm Arenicola marina (L). J Exp Mar Biol Ecol 202:107-118

Riisgård HU, Banta GT (1998) Irrigation and deposit feeding by the lugworm Arenicola marina, characteristics and secondary effects on the environment. A review of current knowledge. Vie Milieu 48:243-257

Riisgård HU, Berntsen I, Tarp B (1996) The lugworm (Arenicola marina) pump: characteristics, modelling and energy cost. Mar Ecol Prog Ser 138:149-156

Rijken M (1979) Food and food uptake in Arenicola marina. Neth J Sea Res 13:406-421

Rocha C, Forster S, Koning E, Eppink E (2005) High-resolution permeability determination and two-dimensional pore-

Editorial responsibility: Otto Kinne (Editor-in-Chief), Oldendorf/Luhe, Germany water flow in sandy sediment. Limnol Oceanogr Methods 3:10-23

Rouse GW, Pleijel F (2001) Polychaetes. University Press, Oxford

Timmermann K, Christensen JH, Banta GT (2002) Modeling of advective solute transport in sandy sediments inhabited by the lugworm Arenicola marina. J Mar Res 60: 151-169

Timmermann K, Banta GT, Larsen J, Andersen O (2003) Modelling particle and solute transport in sediments inhabited by Arenicola marina. Effects of pyrene on transport processes. Vie Milieu 53:187-200

Wells GP (1945) The mode of life of Arenicola marina (L.). J Mar Biol Assoc UK 26:170-207

Zebe E, Schiedek D (1996) The lugworm Arenicola marina: a model of physiological adaptation to life in intertidal sediments. Helgol Meeresunters 50:37-68

Ziebis W, Forster S, Huettel M, Jørgensen BB (1996) Complex burrows of the mud shrimp Callianassa truncata and their geochemical impact in the sea bed. Nature 382:619-622

Submitted: June 17, 2004; Accepted: May 16, 2005

Proofs received from author(s): November 7, 2005 